\title{
A lab-on-a-tip approach to make electroanalysis user-friendly and de- centralized: Detection of copper ions in river water
}

\author{
Stefano Cinti ${ }^{\text {a, }}$, Vincenzo Mazzaracchio a , Gökçe Öztürk ${ }^{\mathrm{b}}$, Danila Moscone ${ }^{\mathrm{a}}$, \\ Fabiana Arduini ${ }^{\text {a }}$ \\ a Department of Chemical Science and Technologies, University of Rome “Tor Vergata", Via della Ricerca Scientifica 1, 00133, Rome, Italy \\ b Department of Analytical Chemistry, Faculty of Pharmacy, Karadeniz Technical University, Trabzon, Turkey
}

\section{H I G H L I G H T S}

- The lab is entirely integrated into a pipette tip.

- User-friendly and cost-effective approach for sensing.

- River water does not need to be filtered nor acidified.

\section{A R T I C L E I N F O}

\section{Article history:}

Received 31 March 2018

Received in revised form 23 April 2018

Accepted 27 April 2018

Available online xxx

\section{Keywords:}

Lab-on-a-tip

Gold electrode

Electroanalysis

Copper

River water

\section{G R A P H I C A L A B S T R A C T}

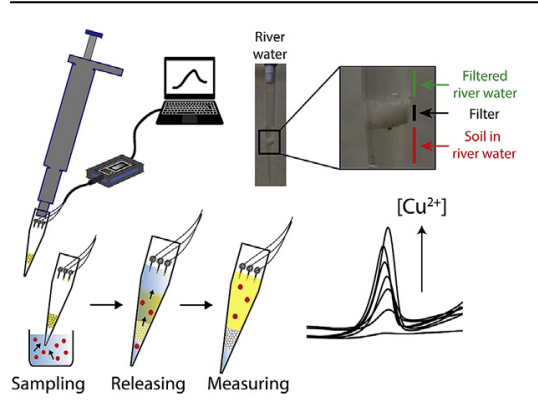

\begin{abstract}
A B S T R A C T
The development of portable and user-friendly sensing platforms is a hot topic in the field of analytical chemistry. Among others, electroanalytical approaches exhibit a high amenability for reaching this purpose, i.e. the commercial strips for diabetes care are an obvious success. However, providing fullyintegrated and user-friendly methods is the leitmotiv. In this work we evaluate the use of a disposable pipette tip, opportunely configured, to realize the first example of lab-on-a-tip. The combination of a pipette tip, wire electrodes, and cotton wool filter, highlights the suitability of producing a novel oneshot electroanalytical platform that does not require expertise-required tasks. To demonstrate the feasibility of this novel method, copper $\left(\mathrm{Cu}^{2+}\right)$ is detected in water samples by means of anodic stripping voltammetry. The quantification is performed directly into the tip that contains a cotton wool filter: the filter has the double function of purifying the matrices from gross impurities and releasing all the preloaded reagents necessary for the assay. After optimizing the experimental parameters, the lab-on-a-tip was capable of detecting $\mathrm{Cu}^{2+}$ linearly up to $300 \mu \mathrm{g} / \mathrm{L}$ with a detection limit of $6.3 \mu \mathrm{g} / \mathrm{L}$. The effectiveness of the platform was confirmed by testing 50,100 , and $150 \mathrm{ppb}$ Cu-spiked river water sample with recovery value comprised between 92 and $103 \%$.
\end{abstract}

(c) 2018 Published by Elsevier B.V.

\footnotetext{
* Corresponding author.

E-mail address: stefano.cinti@uniroma2.it (S. Cinti).
}

\section{Introduction}

Sensing technologies have been tremendously boosted by novel smart materials capable to enhance the performance of the sensing tools like sensitivity, selectivity and reproducibility. In particular, a 
plethora of nanomaterials i.e., gold nanoparticles, graphene, conductive polymers, quantum dots, etc. have been involved in the realization of ultra-sensitive platforms [1-8]. The continually improved combination of cost-effectiveness, disposability, functionality, smart materials, and sustainability represents the primary driver to provide end-users with easy-to-use and effective analytical methods. Among these, the electroanalytical method deserves a main role: they are i) blind towards colored/turbid solutions, ii) deliverable, iii) disposable, iv) require a minimal sample requirement, and v) low-cost. Moreover, the increasing use of filter paper as well-known "active" materials to realize reagent-free platforms helps electroanalysis in satisfying the ASSURED criteria established by WHO [9]. Filter paper, due to its porosity is able to store reagents, purify matrices, and makes species react, enabling a user-friendly and zero-treatment analysis in all the operating fields [10-14].

The development of paper-based point-of-care devices is certainly capable of minimizing (or completely avoiding) tasks for non-specialized users. However, some drawbacks also affect the detection through electrochemical paper-based devices. Even if the effectiveness of filter paper for diagnostics development is not in discussion, the sensitivity of these tools is generally lower than the plastic-based counterpart [15-17]. Obviously, it depends on the specific species detected. Generally, when paper is impregnated, the species contained in the solution move toward the border within the paper network. This radial diffusion typically lowers the amount of detectable molecules, i.e. far from the working electrode. In addition, as recently demonstrated by Merkoci's group, the sensitivity of their electrochemical paper-based platform in heavy metals detection was strictly related to the length of diffusion pathway before the sample had reached the testing area [18]. The step forward in user-friendly diagnostics is represented by the possibility to sample and detect. To date, electroanalysis has been combined with the most diverse materials: pins, 3D-pop up, removable tattoos, film for packaging, etc [15,19-21]. All these examples highlight the suitability of certain materials, generally employed in different context, to be used for the development of electroanalytical platforms. The search of novel materials/scaffolds to be integrated in smart architectures for sensing devices represents a hot topic in analytical chemistry. However, the common feature that guides all these attempts is to provide the nonspecialized users a fully-integrated device, without the requirement of any expertise or sample treatment. For this reason, a pipette tip can represent a valuable breakthrough in the field of electroanalysis. If well configured, a pipette tip can provide an electrochemical cell for in-field analysis, and it can be easily combined with other materials, perhaps exploiting the filtering/ releasing properties of porous supports, i.e. filter paper, cotton.

We propose the development of a novel concept in decentralized electroanalysis. A pipette tip is adopted as the electrochemical cell to perform measurements, and it is customized in order to introduce three-configured $\mu$-electrodes. The Lab-on-a-tip electrochemical device is highly portable: a piece of cotton wool is inserted at the bottom of the tip, allowing both to load the media/ reagents necessary for the assay (the sample will dissolve all the pre-loaded species) and to purify complex matrices, i.e. soil in river water won't reach the electrodes. In 2012, Atakay et al. took advantage of a pipette tip that contained an amine-functionalized sol-gel to enrich and purify phosphopeptides for mass spectroscopy measurements [22]. Even if the authors defined their method as a "lab-in-a-pipet-tip", it should be noted that only one task of the entire experimental procedure for measuring phosphopeptides was contained within the tip, i.e. the pre-enrichment step. Herein, we demonstrate the first example of a fully-enclosed lab-on-a-tip. A pipette tip is combined with a cotton wool filter, and this hybrid platform provides the end-user the entire laboratory. The volume of the tip represents the electrochemical cell and it contains the wire electrodes for the electroanalytical measurements. Instead, the cotton wool encompasses the pre-loaded with all the reagents necessary to carry out the specific assay that are released when the sample is drawn into the tip (the electrochemical cell) and the filtration of the gross impurities that are present in the matrix, i.e. soil, cells, dust. In addition, the lab-on-a-tip approach reported in this work allows to use very low amount of chemicals and sample to analyze, reducing the waste production that is often related to the use of automatized analysis, i.e. continuous flow analysis, flow injection analysis (FIA) [23,24]. In order to demonstrate this novel approach, we selected copper as the model analyte to be detected in river water. Compared to some of the other existing electroanalytical devices for copper ions detection, based on AuNPsmodified gold SPE [25], glassy carbon electrode modified with AuNPs, ferrocene-derivative, and a specific recognition molecule (TPPASH) [26], glassy carbon electrode with MWCNTs, poly(amidoamine) dendrimers, AuNPs and AgNPs [27], our approach offers the unique integrated and customizable tool for metal detection, i.e. copper, easily extensible to other (bio)platforms. After the lab-on-a-tip was characterized by cyclic voltammetry experiments, copper was detected with linear sweep anodic stripping voltammetry linearly in the range comprised between 10 and $300 \mathrm{ppb}$, and satisfactory recovery value was obtained in the tested real sample.

\section{Experimental section}

\subsection{Chemicals and instruments}

Hydrochloric acid, sulfuric acid, potassium ferrocyanide, potassium ferricyanide, potassium chloride, sodium chloride, magnesium chloride, and calcium carbonate were purchased from Sigma Aldrich (USA). Copper and Iron standard solutions for atomic absorption $(1000 \mu \mathrm{g} / \mathrm{L})$ were purchased from Fluka (Germany). The cotton wool filters (Rizla, Ireland) were purchased in local markets. All the solutions were prepared in distillate water. Cyclic voltammetry (CV) and linear sweep anodic stripping voltammetry (LSASV) were performed using a portable PalmSens Instrument (PalmSens, Netherlands) connected to a laptop.

\subsection{Sensor fabrication}

Wires were utilized as the electrodes. In particular, 5-mm gold wires (125- $\mu$ m diameter, A-M systems, USA) were used to make the working and reference electrodes. The shrinkable tubes were utilized to both insulate and define the electrode area. The shrunk tubes appeared stable around the electrode wires used for the development of the entire device. However, a novel electrode was utilized for each measurement. The procedure for the manufacture of the insulated wire was consistent with two steps: i) insulating the wire with the shrinkable tube, and ii) cutting the wire depending on the required length, i.e. $5 \mathrm{~mm}$. The counter electrode was obtained by utilizing a stainless steel wire $(300-\mu \mathrm{m}$ diameter, AISI 316L, GoodFellow, England). All the wires were insulated by applying heat to shrinkable tubing around the body of the wires (PTFE, HS Sub-Lite-Wall ${ }^{\circledR}$, Zeus Industrial Products, Ireland).

\subsection{Lab-on-a-tip}

The experimental set-up is composed by a pipette tip $(1000-\mu \mathrm{L}$ Diamond Tips, Gilson, USA), a piece of cotton wool filter, and the three-configured wire electrodes. First, as shown in Fig. 1A, a small piece of cotton is dipped into a solution that contains the specific reagent, or a mixture of reagents, which is necessary to carry out 

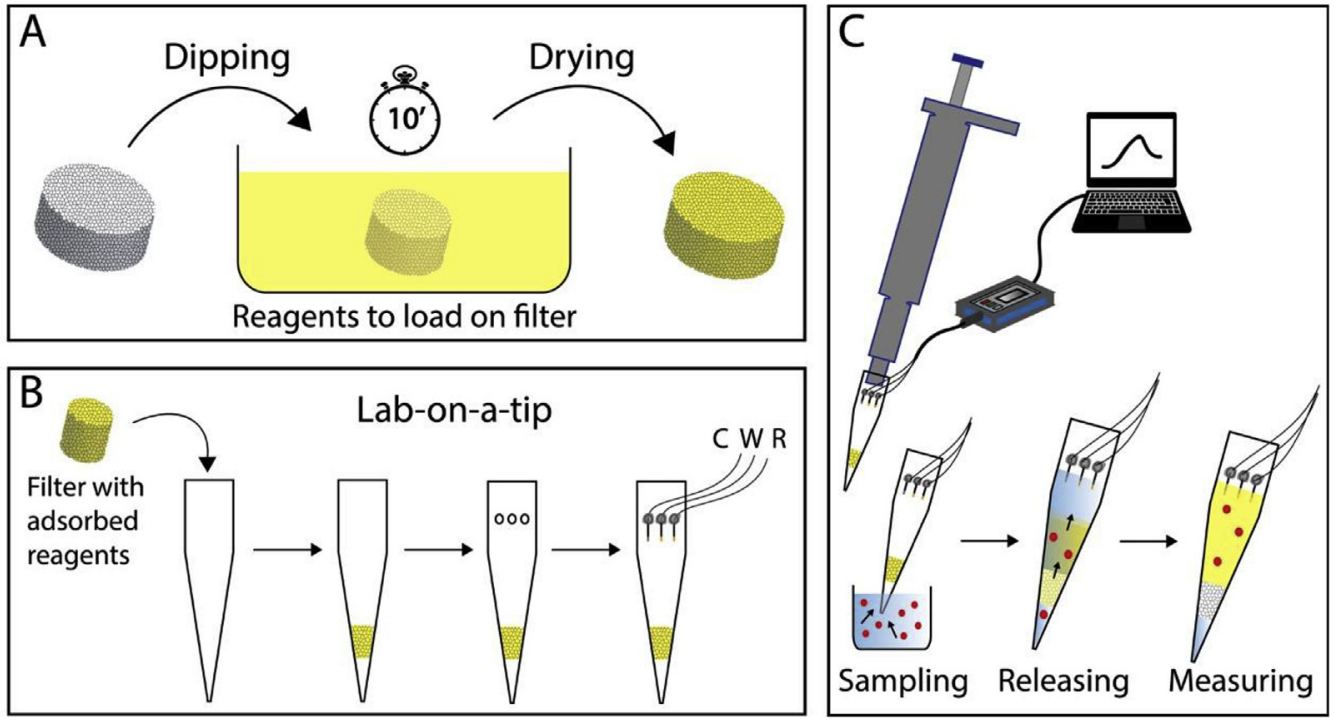

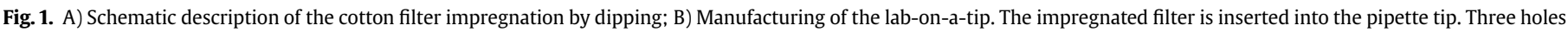
are made on the side of the tip and three wires are inserted into these holes; $\mathrm{C}$ ) Experimental set-up for carry out the measurement.

the final measurements, i.e. in this work both ferro/ferricyanide and hydrochloric acid were loaded within the filter structure. Only the filters with a weight comprises between $(0.045 \pm 0.002) \mathrm{g}$ were selected to proceed with the fabrication of the device. This procedure allows for delivering a sensing system free from memory effect (due to the previous measurements) with increased repeatability.

After the filter is dried, it is inserted into the pipette tip as displayed in Fig. 1B. Subsequently, three holes were made along the pipette tip in order to insert the wire electrodes, using glue to insulate the holes. If the holes are not fully closed, the pipette will not be capable to take the sample up to be analyzed. After, the wires are either connected to a portable potentiostat or wirelessly addressed to a smartphone, and it allows to carry out the quantification directly in-situ. The CV experiments were acquired in the potential range comprised between -0.9 and $0.8 \mathrm{~V}$, varying the scan rate from 20 to $1000 \mathrm{mV} / \mathrm{s}$, and recording 2 scans for each scan rate. The LS-ASV experiments were carried out by conditioning the electrode at $0.4 \mathrm{~V}$ for $30 \mathrm{~s}$, by applying a deposition potential of $-0.4 \mathrm{~V}$ for $200 \mathrm{~s}$, and using a step potential equal to $0.01 \mathrm{~V}$ and a scan rate of $0.8 \mathrm{~V} / \mathrm{s}$. When the sample is drawn by the pipette tip, it encounters the wool cotton filter where the reagents have been pre-loaded. The reagents are released from the filter, producing the desired working solution (Fig. 1C). Moreover, the presence of filter prevents gross impurities from interfering with the measurements, i.e. sticking on the electrodes.

\section{Results and discussions}

\subsection{Electrochemical characterization of the wire electrodes}

After the three-electrode configured system was set-up, the chosen platform was characterized. This study was carried out through cyclic voltammetry analysis in presence of a conventional redox couple, i.e. ferrocyanide/ferricyanide $\left(\mathrm{Fe}(\mathrm{CN}) 6_{6}^{4-} / \mathrm{Fe}(\mathrm{CN})_{6}^{3-}\right)$. The measurements were carried out with $100 \mu \mathrm{L}$ of a $0.1 \mathrm{M}$ potassium chloride solution that contained $2 \mathrm{mM}$ of the redox couple. Fig. 2 displays the anodic and cathodic current densities registered varying the scan rate in the $20-1000 \mathrm{mV} / \mathrm{s}$ range.

As highlighted, the voltammetric peaks appear to be dependent

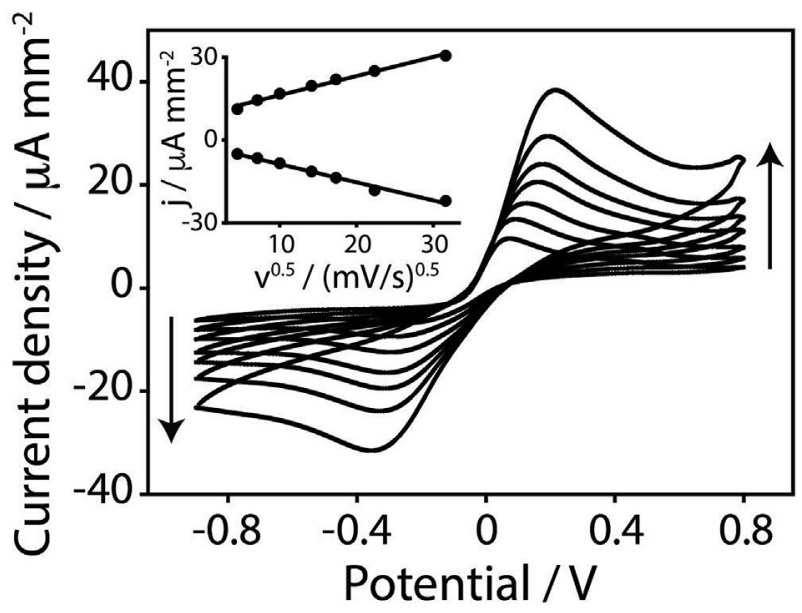

Fig. 2. Cyclic voltammetry experiments performed with $2 \mathrm{mM}\left[\mathrm{Fe}(\mathrm{CN})_{6}\right]^{4-/ 3-}$ prepared in $0.1 \mathrm{M} \mathrm{KCl}$ varying the scan rate from 20 to $1000 \mathrm{mV} / \mathrm{s}$. Inset i) Current intensities vs. (scan rate) ${ }^{0.5}$ acquired in $2 \mathrm{mM}\left[\mathrm{Fe}(\mathrm{CN})_{6}\right]^{4-/ 3-}$ varying the scan rate from 20 to $1000 \mathrm{mV}$ /

on the scan rate magnitude. The anodic and cathodic currents increased with the square root of the scan rate, indicating an electrode reaction controlled by mass transport (semi-infinite linear diffusion) [28-30]. A linear regression has been obtained both for the anodic and cathodic current densities $\left(\mathrm{j}_{\mathrm{p}}\right)$ and the square root of the scan rate $(v)$, respectively, equal to jp $(\mu \mathrm{A} /$ $\left.\mathrm{mm}^{2}\right)=9.3+0.72 v^{0.5}\left((\mathrm{mV} / \mathrm{s})^{0.5}\right)$ and $\mathrm{j}_{\mathrm{p}}\left(\mu \mathrm{A} / \mathrm{mm}^{2}\right)=-2.2+0.66$ $v^{0.5}\left((\mathrm{mV} / \mathrm{s})^{0.5}\right)$. The anodic-to-cathodic ratio is not unity and the peak position changes for increasing values of scan rate differently from simple reversible couple.

\subsection{Detection of copper ions at the wire electrodes}

Prior to the implementation of the lab-on-a-tip approach, the wire electrodes were tested for the detection of copper ions in $0.1 \mathrm{M}$ hydrochloric acid. Copper ions were detected by using linear-sweep anodic stripping voltammetry as the analytical technique. The experimental parameters related to the stripping method was 
evaluated. In particular, the deposition time (from 100 to $400 \mathrm{~s}$ ), the deposition potential (from -0.3 to $-0.5 \mathrm{~V}$ ), and the effect of the scan rate (from 0.6 to $1 \mathrm{~V} / \mathrm{s}$ ) were examined, as reported in Figure S1 (Supporting Information). The experimental conditions of $200 \mathrm{~s},-0.4 \mathrm{~V}$, and $0.8 \mathrm{~V} / \mathrm{s}$, respectively for deposition time, deposition potential, and scan rate, represented the optimal compromise in terms of sensitivity and time of measurements, and were chosen to carry out the copper detection. As reported in Figure S2 (Supporting Information), the satisfactory performance of the wireconfigured electrodes with regard to the determination of $\mathrm{Cu}(\mathrm{II})$ is confirmed by a regression equation equal to $\mathrm{j}\left(\mu \mathrm{A} / \mathrm{mm}^{2}\right)=-$ $(0.129 \pm 0.009)+(0.009 \pm 0.001)[\mathrm{Cu}(\mathrm{II})](\mathrm{ppb})$, where $\mathrm{y}$ and $\mathrm{x}$ indicate, respectively, the current density in $\mu \mathrm{A} / \mathrm{mm}^{2}$ and the $[\mathrm{Cu}(\mathrm{II})]$ in ppb, with a $\mathrm{R}^{2}$ of 0.9921 , a sensitivity of $0.009 \pm 0.001 \mu \mathrm{A} /$ $\mathrm{ppb} \mathrm{mm}^{2}$, a limit of detection of $5.2 \mathrm{ppb}$ (calculated equal to $3 \sigma_{\mathrm{B}} /$ slope, where $\sigma_{B}$ is the standard deviation of three independent blank measurements), and a linear range up to $300 \mathrm{ppb}$ with an inter-assay variation $<7 \%$ (calculated as the relative standard deviation).

\subsection{Lab-on-a-tip}

\subsubsection{Releasing properties of the cotton wool filter}

To completely enclose an analytical tool into a pipette tip, all the reagents need to be pre-loaded onto an adsorbent substrate. This should guarantee to load a high amount of a chosen molecule (or mixture of species) and, consequently, to be suitable in releasing that before the detection. To deal with this issue, a commercially available filter for cigarette rolling was used. Besides its high adsorbing properties, its structure behaves as a filter for the gross impurities that may be present in the matrices, i.e. soil in the river, and that may affect the detection at the electrode. As displayed in Fig. 3, when the solution is sampled the filter releases the preloaded species.

To evaluate the releasing properties, the filter contained into the pipette tip was dipped into a solution containing a mixture of ferro/ ferricyanide $(50 \mathrm{mM})$ for $10 \mathrm{~min}$. Different dipping times were interrogated, i.e. from 5 to $20 \mathrm{~min}$. The impregnation of the filter for a time longer than $10 \mathrm{~min}$ did not lead to a significant increase in terms of the adsorbed, and the subsequently released, ferro/ferricyanide into the pipette tip. In addition to the cotton wool filter, also another kind of material was used to evaluate its efficacy for

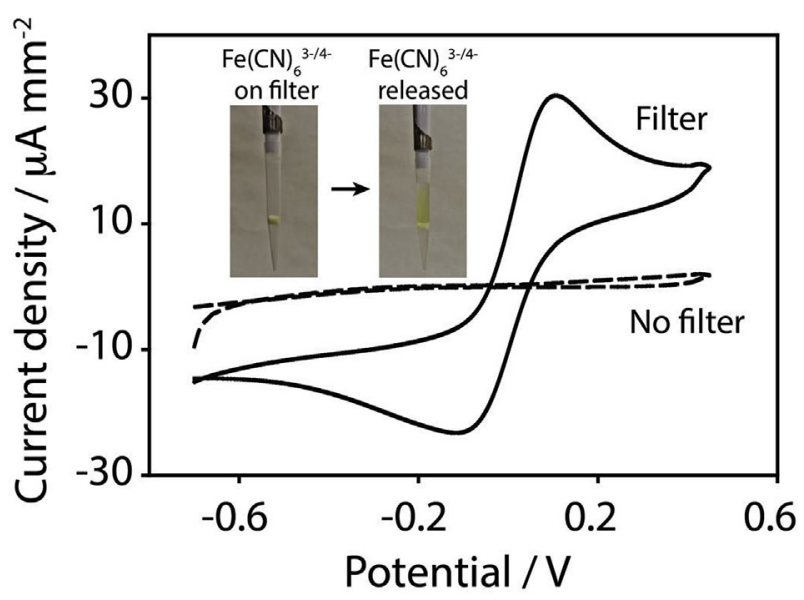

Fig. 3. Releasing properties of the cotton filter that was dipped for $10 \mathrm{~min}$ into a $50 \mathrm{mM}$ ferro/ferricyanide solution. Cyclic voltammetry by pipetting and analyzing $500 \mu \mathrm{L}$ of water in absence (dashed line) and in presence (solid line) of the impregnated filter into the pipette tip. Scan rate of $50 \mathrm{mV} / \mathrm{s}$. The photographs show the release of the adsorbed species from the filter when the sample is drawn into the pipette. realizing this tip-based method: impact absorbing foam that is usually adopted to absorb shock or impact. However, this material did not allow a satisfactory adsorption of the solution within its porous structure (not shown). After the filter was dried, $500 \mu \mathrm{L}$ of water were drawn and a cyclic voltammetry was recorded, demonstrating the effective release of the adsorbed species by the filter. In addition, in the presence of the impregnated cotton wool filter the adsorbed species were released immediately and, after just a minute, the pipette tip is almost entirely colored and visible to the naked eye. Also the measuring time was evaluated after the filter released the adsorbed species: specifically, the optimal time to perform the measurement was found to be after $60 \mathrm{~s}$. This time was attributable to the diffusion of the species released from the filter, required to form a homogenous solution.

\subsubsection{Detection of copper ions in standards}

In order to develop a lab-on-a-tip approach, all the reagents should necessarily be enclosed within it. As previously observed, a finely cut wool cotton filter can be loaded with certain species that are successively released and analyzed, i.e. ferro/ferricyanide mixture. Herein, to allow the end-user detecting copper ions without adding chemicals, the supporting media needs to be already present in the pipette tip. The supporting media, i.e. hydrochloric acid, is loaded within the filter. Because the $\mathrm{pH}$ plays a key-role toward the detection of metallic ions, the filter has been dipped in three different concentration of hydrochloric acid, namely $0.5,1$, and $2 \mathrm{M}$ (Fig. 4).

Besides the hydrochloric acid concentration, the dipping time was also investigated. The filter was dipped for 5,10 , and $20 \mathrm{~min}$ before it was dried into an oven at $40^{\circ} \mathrm{C}$. Among these dipping times, 10 -min resulted that time capable to provide a satisfactory adsorption of molecules within the shortest time. By using this time for impregnating the filter with the chosen molecules, the optimal concentration of hydrochloric acid was evaluated, and $1 \mathrm{M}$ was chosen because of its better repeatability (relative standard deviation equal to $6 \%$ ) for different measurements $(n=3)$.

After all the experimental parameters (dipping time, $\mathrm{HCl}$ concentration) were optimized, the lab-on-a-tip approach has been interrogated towards the detection of copper ions. In order to realize the fully integrated system, as previously described in Fig. 1, the three wires were inserted into the pipette tip and insulated

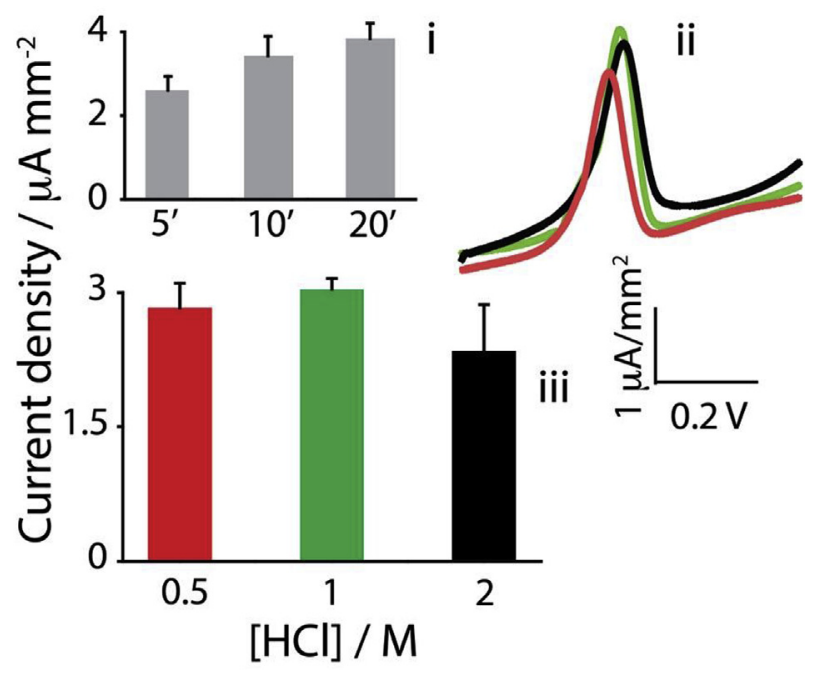

Fig. 4. Optimization procedure regarding i) the time of dipping of the filter $(5,10$, and $20 \mathrm{~min})$ and ii,iii) the concentration of the hydrochloric acid to adsorb $(0.5,1$, and $2 \mathrm{M})$, in presence of $300 \mu \mathrm{g} / \mathrm{L}$ of copper ions. 


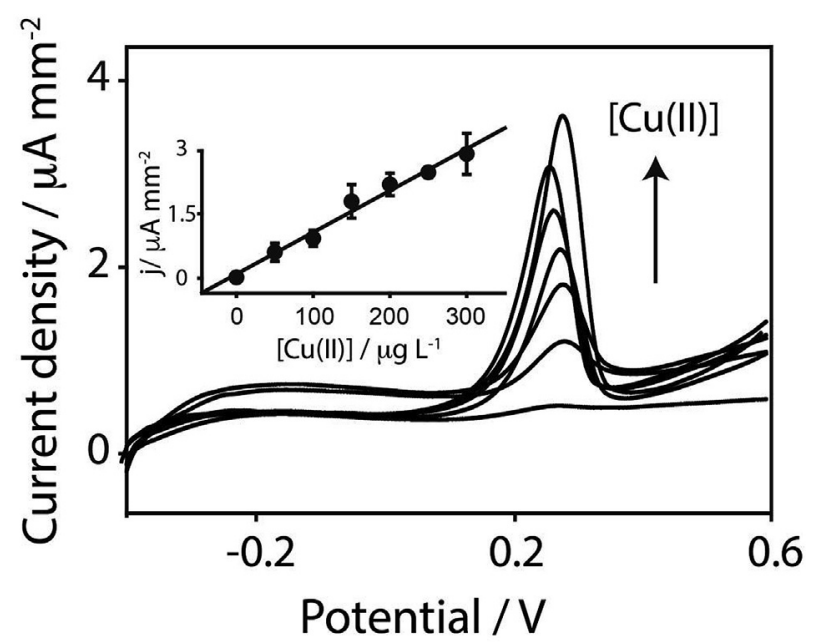

Fig. 5. Voltammetric curves obtained with ASV analyzing copper ions in the range comprised between 0 and $300 \mu \mathrm{g} / \mathrm{L}$ prepared in distilled water by using the lab-on-atip approach. Inset: Calibration curve obtained by analyzing copper ions in the range comprised between 0 and $300 \mu \mathrm{g} / \mathrm{L}$ prepared in distilled water. Measurements were performed by drawing $500 \mu \mathrm{L}$ of the sample to analyze. Operative conditions: $\mathrm{E}$ cond. $=0.4 \mathrm{~V}$; t cond. $=30 \mathrm{~s}$; E dep. $=-0.4 \mathrm{~V}$; t dep. $=200 \mathrm{~s}$; E step $=0.01 \mathrm{~V}$; Scan rate $=0.8 \mathrm{~V} / \mathrm{s}$.

with glue (Figure S3, Supporting Information). To carry out the measurements within the lab-on-a-tip device, a different filter was used for each copper quantification, making this approach oneshot. However, the paper-based nature of the cotton wool filter offers a valuable and sustainable alternative for the realization of this class of devices: the filter can be easily incinerated, lowering the waste management and its accumulation. As shown in Fig. 5, a calibration curve has been obtained by sampling distilled water spiked with known concentration of copper ions.

The current density ( $\mathrm{j}$, expressed in $\mu \mathrm{A} / \mathrm{mm}^{2}$ ) is linearly correlated to the concentration of copper ions ([Cu(II)], expressed in $\mathrm{ppb}$ ) through the following regression equation: $\mathrm{j}\left(\mu \mathrm{A} / \mathrm{mm}^{2}\right)=-$ $(0.097 \pm 0.006)+(0.010 \pm 0.001)[\mathrm{Cu}(\mathrm{II})](\mathrm{ppb})\left(\mathrm{R}^{2}=0.9823\right)$. The detection limit, calculated as $3 \sigma_{\mathrm{B}} /$ slope, resulted equal to $6.3 \mathrm{ppb}$ and the response appeared linear up to $300 \mathrm{ppb}$. By comparing these analytical results with those obtained by analyzing the copper ions in acidified standard solutions, without the Lab-on-a-tip approach, (Figure S2, Supporting Information), it is obvious how both the sensitivity, the linear range, and the detection limit are roughly the same. It depends on the effective releasing properties of the filter that is contained inside the pipette tip. This approach offers a novel way to develop a fully integrated method: differentiating from the reagent-free paper-based electrochemical assays that employ filter paper as the substrate for electrodes manufacturing, the particular experimental set-up adopted for the lab-on-a-tip avoids the drawbacks related to the decrease of sensitivity. In comparison with the recent electrochemical-based method for copper ions detection, the lab-on-a-tip allows the end-user to avoid all the procedures related to the sample treatments (management of chemicals, $\mathrm{pH}$ adjustment, filtration, dilution, etc.) and the analytical performances appear to be positively comparable with those reported in Table 1.

\subsubsection{Application towards real matrix}

The principal aspects that are related to the development of this fully integrated approach for in-situ application, are consistent with its user-friendly nature and the possibility to avoid sample filtration, e.g. cells in whole blood as well as soil in river water can interfere with the electrodes' surface. To highlight the multitasking attitude of the lab-on-a-tip, we tested the concept for the quantification of copper ions in river water (Aniene River, Rome). River water can contain particulate, i.e. soil, and as shown in Fig. 6A, the effect of the cotton wool filter is highly relevant.

Besides the reagent loading, the filter that is integrated into the pipette tip was able to filter all the gross impurities, preventing them to collide with the electrodes. The effectiveness of the ultimate lab-on-a-tip device has been evaluated in river water samples, which have been analyzed without further filtration nor $\mathrm{pH}-$ adjustment, as shown in Fig. $6 \mathrm{~B}$ and $\mathrm{C}$. The matrix effect was evaluated by measuring the signal from copper ions in $0.1 \mathrm{M} \mathrm{HCl}-$ acidified river water obtaining a sensitivity of $0.012 \pm 0.001 \mu \mathrm{A} /$ $\mathrm{ppb} \mathrm{mm}^{2}$. Even if a slightly difference of the mean value of sensitivity was observed if compared with that one obtained by drawing distilled water, the sensitivities appeared similar within the experimental error. This could be ascribable to the composition of river water: it is mainly composed by ionic species that cannot be blocked by the filter in the tip, i.e. Calcium, Iron, Magnesium, Sodium, etc., and the presence of these species in form of ions might contribute to a greater ion strength, compared to the distilled water used to develop the method, which is reflected in slightly higher

Table 1

Lab-on-a-tip vs existing electrochemical platforms towards Copper ions detection.

\begin{tabular}{|c|c|c|c|c|c|c|}
\hline Platform & Method & LOD & Linearity & Real matrices & Operative procedures & Ref \\
\hline Au SPE-AuNPs & $\begin{array}{l}\text { SW- } \\
\text { ASV }\end{array}$ & $1.6 \mathrm{ppb}$ & $20-300 \mathrm{ppb}$ & 1 & Working solution needs to be stirred in $0.1 \mathrm{M}(\mathrm{pH} 4.5)$ acetate buffer. & [25] \\
\hline GC/Au/TPAASH + FcHT. & DPV & $5 \mathrm{ppb}$ & 40- $690 \mathrm{ppb}$ & Rat microdialysates brain & $\begin{array}{l}\text { Working solution needs to be deaerated }\left(\mathrm{N}_{2}\right) \text {. The working solution is } \\
0.1 \mathrm{M} \text { artificial cerebrospinal fluid }(\mathrm{pH} 7.4) \text {. }\end{array}$ & [26] \\
\hline $\begin{array}{l}\text { GCE-MWCNTs-PAMAM } \\
\text { AuNPs-AgNPs }\end{array}$ & DPV & $0.3 \mathrm{ppb}$ & $0.6-63 \mathrm{ppb}$ & Tap and lake waters & $\begin{array}{l}400 \mu \mathrm{L} \text { of } \mathrm{Cu} 2+\text { solution or sample was mixed with } 400 \mu \mathrm{L} \text { of } 15 \mu \mathrm{M} \text { Cys } \\
\text { in } 100 \mathrm{mM} \text { pH } 7.4 \text { Tris- } \mathrm{HCl} \text { buffer for } 30 \text { min to perform the catalytic } \\
\text { oxidation of Cys by dissolved oxygen. Then, } 200 \mu \mathrm{L} \text { of } 0.1 \mu \mathrm{M} \text { AgNPs was } \\
\text { added into the mixture and incubated for } 10 \mathrm{~min} \text {. After the sensor was } \\
\text { immersed in the mixture and incubated for } 30 \text { min under stirring, } \\
\text { differential pulse voltammetric (DPV) measurement was performed in } \\
0.1 \mathrm{M} \text { Tris- } \mathrm{HCl}(\mathrm{pH} \text { 7.4). All the samples are filtered through a } 0.2 \mu \mathrm{m} \\
\text { membrane. }\end{array}$ & [27] \\
\hline Au coated Al-plate pT-IDA & SWV & $4 \mathrm{ppb}$ & $6-600 \mathrm{ppb}$ & 1 & $\begin{array}{l}\text { Working solution needs to be stirred acetate buffer. Each electrode is } \\
\text { rinsed with EDTA. }\end{array}$ & [31] \\
\hline $\mathrm{Mo}_{6} \mathrm{~S}_{9-\mathrm{x}} \mathrm{I}_{\mathrm{x}} \mathrm{NWs} / \mathrm{GCE}$ & DP-ASV & $0.20 \mathrm{ppb}$ & $\begin{array}{l}0.8 \\
-240 \mathrm{ppb}\end{array}$ & Tap water & $\begin{array}{l}\text { Working solution needs to be stirred in } 0.1 \mathrm{M} \text { ( } \mathrm{pH} 4.7 \text { ) acetate buffer. } \\
\text { Tap water is condensed (pre-conc.) and mixed with } 0.2 \mathrm{M} \text { acetate buffer. }\end{array}$ & [32] \\
\hline Lab-on-a-tip Gold wires & LS-ASV & $6 \mathrm{ppb}$ & $20-300 \mathrm{ppb}$ & River water & None & This Work \\
\hline
\end{tabular}

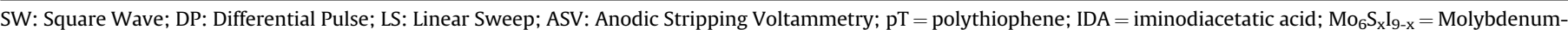

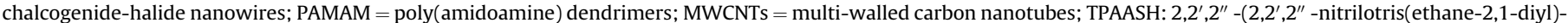
tris((pyridin-2 ylmethyl)azanediyl)triethanethiol; FcHT:Tris(2-aminoethyl)amine, 6-(ferrocenyl) hexanethiol. 


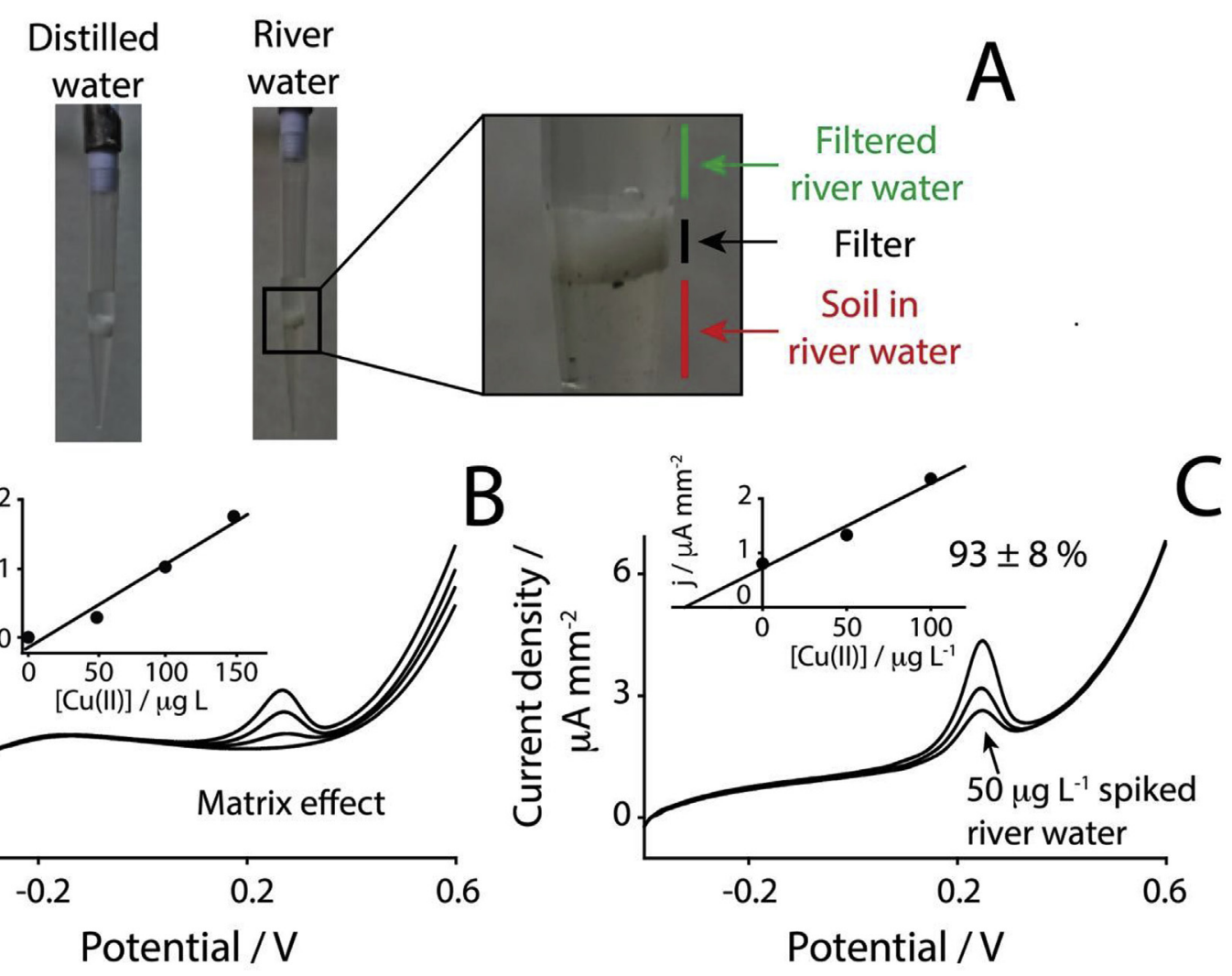

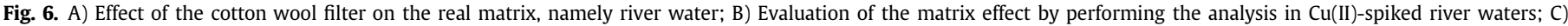
Recovery experiments carried out by spiking river water with $50 \mu \mathrm{g} / \mathrm{L}$. Operative conditions equal as reported in caption of Fig. 5 .

Table 2

Percentage recoveries for 50, 100, and 150 ppb Cu-spiking of Aniene River water.

\begin{tabular}{lll}
\hline Added $\mathrm{Cu}(\mathrm{II}) / \mathrm{ppb}$ & Founded $\mathrm{Cu}(\mathrm{II}) / \mathrm{ppb}$ & \% Recovery \\
\hline 50 & $46 \pm 4$ & $92 \pm 8$ \\
100 & $103 \pm 10$ & $103 \pm 10$ \\
150 & $147 \pm 13$ & $98 \pm 9$ \\
\hline
\end{tabular}

currents. However, interference studies were carried out by analyzing solution containing $10 \mathrm{mM}$ sodium chloride, $10 \mathrm{mM}$ calcium carbonate, $10 \mathrm{mM}$ magnesium chloride and $50 \mathrm{ppb}$ Iron. Compared with $100 \mathrm{ppb}$ of Copper ions, these species only produced a slight increase of the background current (Figure S4, Supporting Information). After having established the not presence of copper ions at the detection limit of the system (i.e. $6.3 \mathrm{ppb}$ ) in the chosen matrix, recovery experiments were carried out in order to evaluate the accuracy of the lab-on-a-tip approach. Water sampled from Aniene river was spiked with 50,100, and $150 \mathrm{ppb}$ of copper ions, and through the standard addition method (50 and $100 \mathrm{ppb}$ ), the electrochemical lab-on-a-tip device was capable to quantify the initial concentration of copper and the percentage recoveries were equal, respectively to $92 \pm 8,103 \pm 10$, and $98 \pm 9 \%$. The values are reported in Table 2.

\section{Conclusions}

The first example of a fully integrated electrochemical Lab-on-atip device has been reported. This approach opens to a plethora of opportunities toward the realization of de-centralized tools. Just by using very common (and commercially available) materials such as a pipette tip, a cotton wool filter and some conductive wires, it has been possible to develop an affordable analytical device for use by non-specialists. This work highlights the potential application of this approach which is started from those "everyday" materials. A pipette tip has been engineered as the electrochemical cell and a cotton wool filter, generally adopted for other purposes, has been used both to load the reagents necessary for the assay and to filter the gross impurities present in the real matrices. As the case study, copper ions have been determined in river water. This approach can be applied to detect other species, even in biological matrices such as blood, serum, sweat, etc. All the components can be finely customized depending on the particular application, i.e. enzymes, nucleic acids, antibodies, can be loaded onto a porous materials and, consequently, integrated into a pipette tip. Even if the results appear promising in terms of de-centralized application, these preliminary finding should be further investigated. Perhaps, the use of smaller tips might represent the next step, even if the experimental set-up should be carefully evaluated. The positioning of the three wire electrodes is strictly dependent on the available space within the tip. 3D-printing can be successfully exploited to improve this approach, for instance by printing ad-hoc pipette tips that are capable to provide an optimal space for the wires electrodes. Another parameter to be considered for future development is the adaptability of this approach to detect molecules bigger than metal ions, i.e. protein, nucleic acids. However, the possibility in using different porosity (and chemistry) filters represents a valuable feature to improve the customization of the Lab-on-a-tip depending on the specific needs. In addition, the use of deposition techniques such as screen-printing, inkjet printing, sputtering, might lead to the development of fully-printed and disposable devices. 


\section{Acknowledgements}

Julian Ramirez for proofreading the manuscript. S.C. would like to thank Prof. L. Falciola (University of Milan) for his friendship and for the helpful discussion.

\section{Appendix A. Supplementary data}

Supplementary data related to this article can be found at https://doi.org/10.1016/j.aca.2018.04.065.

\section{References}

[1] K. Saha, S.S. Agasti, C. Kim, X. Li, V.M. Rotello, Gold nanoparticles in chemical and biological sensing, Chem. Rev. 112 (2012) 2739-2779.

[2] E. Morales-Narváez, L.F. Sgobbi, S.A.S. Machado, A. Merkoçi, Grapheneencapsulated materials: synthesis, applications and trends, Prog. Mater. Sci. 86 (2017) 1-24.

[3] E. Morales-Narváez, L. Baptista-Pires, A. Zamora-Gálvez, A. Merkoçi, Graphene-based biosensors: going simple, Adv. Mater. 29 (2017) 1604905-1604910.

[4] P. Yáñez-Sedeño, S. Campuzano, J.M. Pingarrón, Electrochemical sensors based on magnetic molecularly imprinted polymers: a review, Anal. Chim. Acta 960 (2017) 1-17.

[5] Z.H. Jin, Y.L. Liu, J.J. Chen, S.L. Cai, J.Q. Xu, W.H. Huang, Conductive polymercoated carbon nanotubes to construct stretchable and transparent electrochemical sensors, Anal. Chem. 89 (2017) 2032-2038.

[6] S. Cinti, F. Arduini, Graphene-based screen-printed electrochemical (bio) sensors and their applications: efforts and criticisms, Biosens. Bioelectron. 89 (2017) 107-122.

[7] J. Wang, W. Gao, Nano/microscale motors: biomedical opportunities and challenges, ACS Nano 6 (2012) 5745-5751.

[8] S. Cinti, Polymeric materials for printed-based electroanalytical (bio) applications, Chemosensors 5 (2017) 31-46.

[9] M. Urdea, L.A. Penny, S.S. Olmsted, M.Y. Giovanni, P. Kaspar, A. Shepherd A.P. Wilson, C.A. Dahl, S. Buchsbaum, G. Moeller, D.C.H. Burgess, Requirements for high impact diagnostics in the developing world, Nature 444 (2006) $73-79$.

[10] Y. Yang, E. Noviana, M.P. Nguyen, B.J. Geiss, D.S. Dandy, C.S. Henry, Paperbased microfluidic devices: emerging themes and applications, Anal. Chem. 89 (2016) 71-91.

[11] A.M. López-Marzo, A. Merkoçi, Paper-based sensors and assays: a success of the engineering design and the convergence of knowledge areas, Lab a Chip 16 (2016) 3150-3176.

[12] Z. Nie, C.A. Nijhuis, J. Gong, X. Chen, A. Kumachev, A.W. Martinez M. Narovlyansky, G.M. Whitesides, Electrochemical sensing in paper-based microfluidic devices, Lab a Chip 10 (2010) 477-483.

[13] W. Dungchai, O. Chailapakul, C.S. Henry, Electrochemical detection for paperbased microfluidics, Anal. Chem. 81 (2009) 5821-5826.

[14] F. Arduini, S. Cinti, V. Scognamiglio, D. Moscone, Paper-based electrochemical devices in biomedical field: recent advances and perspectives in past, presen and future challenges of biosensors and bioanalytical tools in analytical chemistry: a tribute to professor marco mascini, Compr. Anal. Chem. 77 (2017) 385-413.

[15] C.C. Wang, J.W. Hennek, A. Ainla, A.A. Kumar, W.J. Lan, J. Im, B.S. Smith, M. Zhao, G.M. Whitesides, A paper-based "pop-up" electrochemical device for analysis of beta-hydroxybutyrate, Anal. Chem. 88 (2016) 6326-6333.

[16] S. Cinti, C. Minotti, D. Moscone, G. Palleschi, F. Arduini, Fully integrated readyto-use paper-based electrochemical biosensor to detect nerve agents, Biosens. Bioelectron. 93 (2017) 46-51.

[17] S. Cinti, L. Fiore, R. Massoud, C. Cortese, D. Moscone, G. Palleschi, F. Arduini, Low-cost and reagent-free paper-based device to detect chloride ions in serum and sweat, Talanta 179 (2018) 186-192.

[18] M. Medina-Sánchez, M. Cadevall, J. Ros, A. Merkoçi, Eco-friendly electrochemical lab-on-paper for heavy metal detection, Anal. Bioanal. Chem. 407 (2015) 8445-8449.

[19] A.C. Glavan, A. Ainla, M.M. Hamedi, M.T. Fernández-Abedul, G.M. Whitesides, Electroanalytical devices with pins and thread, Lab a Chip 16 (2016) 112-119.

[20] J. Kim, I. Jeerapan, S. Imani, T.N. Cho, A. Bandodkar, S. Cinti, P.P. Mercier, J. Wang, Noninvasive alcohol monitoring using a wearable tattoo-based iontophoretic-biosensing system, ACS Sens. 1 (2016) 1011-1019.

[21] S. Cinti, V. Mazzaracchio, I. Cacciotti, D. Moscone, F. Arduini, Carbon blackmodified electrodes screen-printed onto paper towel, waxed paper and parafilm $\mathrm{M}^{\circledR}$, Sensors 17 (2017) 2267-2278.

[22] M. Atakay, O. Celikbıcak, B. Salih, Amine-functionalized sol-gel-based lab-ina-pipet-tip approach for the fast enrichment and specific purification of phosphopeptides in MALDI-MS applications, Anal. Chem. 84 (2012) $2713-2720$

[23] D. Talarico, S. Cinti, F. Arduini, A. Amine, D. Moscone, G. Palleschi, Phosphate detection through a cost-effective carbon black nanoparticle-modified screenprinted electrode embedded in a continuous flow system, Environ. Sci. Technol. 49 (2015) 7934-7939.

[24] M.C.T. Diniz, O.F. Filho, E.V. de Aquino, J.J.R. Rohwedder, Determination of phosphate in natural water employing a monosegmented flow system with simultaneous multiple injection, Talanta 62 (2004) 469-475.

[25] H. Wan, O Sun, H. Li, F. Sun, N. Hu, P. Wang, Screen-printed gold electrode with gold nanoparticles modification for simultaneous electrochemical determination of lead and copper, Sens. Actuators, B 209 (2015) 336-342.

[26] L. Zhang, Y. Han, F. Zhao, G. Shi, Y. Tian, A selective and accurate ratiometric electrochemical biosensor for monitoring of $\mathrm{Cu}^{2+}$ ions in a rat brain, Anal. Chem. 87 (2015) 2931-2936.

[27] L. Cui, J. Wu, J. Li, Y. Ge, H. Ju, Electrochemical detection of $\mathrm{Cu}^{2+}$ through $\mathrm{Ag}$ nanoparticle assembly regulated by copper-catalyzed oxidation of cysteamine, Biosens. Bioelectron. 55 (2014) 272-277.

[28] R.G. Compton, C.E. Banks, Understanding Voltammetry, second ed., World Scientific Publishing Company, 2007.

[29] A.J. Bard, L.R. Faulkner, Electrochemical Methods: Principles and Applications, Wiley, 2001.

[30] J. Wang, Analytical Electrochemistry, third ed., Wiley-VCH, 2006.

[31] M. Lin, M. Cho, W.S. Choe, Y. Son, Y. Lee, Electrochemical detection of copper ion using a modified copolythiophene electrode, Electrochim. Acta 54 (2009) 7012-7017.

[32] H. Lin, M. Li, D. Mihailovič, Simultaneous determination of copper, lead, and cadmium ions at a $\mathrm{Mo}_{6} \mathrm{~S}_{9-\mathrm{x}} \mathrm{I}_{\mathrm{x}}$ nanowires modified glassy carbon electrode using differential pulse anodic stripping voltammetry, Electrochim. Acta 154 (2015) 184-189. 